\title{
Hard Inclusions in Armature Brass
}

\author{
Remigiusz Romankiewicz ${ }^{\mathrm{a} *}$, Ferdynand Romankiewicz ${ }^{\mathrm{b}}$ \\ aUniversity of Zielona Góra, Faculty of Mechanical Engineering, Licealna St. 9, 65-417, Zielona Góra \\ ${ }^{\mathrm{b}}$ Retired Professor \\ *e-mail: r.romankiewicz@ibem.uz.zgora.pl
}

Received: 7 July 2019/Accepted: 9 August 2019/Published online: 18 September 2019

This article is published with open access by AGH University of Science and Technology Press

\begin{abstract}
The influence of the chemical composition of selected armature brasses on the formation of hard inclusions was investigated. In metallographic studies using optical microscopy and scanning electron microscopy with X-ray microanalysis (EDS), it was found that hard inclusions attain sizes ranging from several hundred nanometers to several micrometers. Investigations of samples that were taken from metallurgical pigs of armature brass of various chemical compositions have shown that the contribution of components such as iron and silicon have a decisive influence on the formation of hard inclusions. These components have a dominant share in hard inclusions (60-76 wt.\% Fe and 10.6-17.4 wt.\% Si). In much smaller quantities there are also elements such as manganese, phosphorus, nickel and chromium. The chemical composition of hard inclusions varies. The number and size of hard inclusions depends on the contribution of iron and silicon brass. In the brass sample with 0.31 wt.\% Fe and 0.08 wt.\% Si, 1183 inclusions per square millimeters were identified, while in the brass sample with 0.21 wt.\% Fe and 0.11 wt.\% Si the amount of hard inclusions was reduced to 933 inclusions per square millimeters. In the brass sample with reduced iron content up to $0.08 \mathrm{wt} . \%$ and silicon up to $0.006 \mathrm{wt} . \%$, no hard inclusions were identified.
\end{abstract}

\section{Keywords:}

armature brass, hard inclusions, chemical composition, X-ray microanalysis

\section{INTRODUCTION}

The brass grades used for the making of armatures are generally characterized by a large share of compound intermetallic phases commonly known as hard inclusions. These inclusions are characterized by a high hardness [1,2] and can reach sizes up to several micrometers. Hard inclusions in armature brass achieve hardness much higher than the hardness of the matrix in the armature brass structure. During machining, the inclusions cause an accelerated wear on machining tools and make it difficult to achieve a satisfactory smoothness of the product surfaces as a result of removing it from the brass matrix using cutting tools. These inclusions have a particularly unfavorable effect on the polishing of brass products, because after breaking out of the brass matrix, they constitute hard particles in the polishing paste, the dimensions of which significantly exceed the size of the grains of the materials constituting the components of the polishing paste. As a consequence, they cause scratching of the polished surface of brass products. Often occurring after the polishing process, scratches on the surface of the products and cavities created as a result of the chipping from hard inclusions from the brass matrix, significantly impede the processes of galvanic nickel plating and chrome plating.

In the hollows created after the crushing of hard inclusions, so-called "Comets" filled with polishing material are formed in the process of polishing. This eliminates a large number of castings from the production process, especially when a high smoothness of polished surfaces is required.

From the previous studies of hard inclusions in armature brass, it seems that they are characterized by a large diversity both in terms of quantity, size, form and chemical composition $[3,4]$. The sizes of hard inclusions are in the range from several hundred nanometers to several micrometers. Their contribution in armature brass varies considerably and can range from a few to over 1500 per square millimeters. Quantitative restrictions are generally limited to $0.5 \mathrm{wt} . \%$ of the surface area of the sample or less than 400 per square millimeters. High quality armature brass contains few hard $\left(<100 / \mathrm{mm}^{2}\right)$ inclusions with a size less than $500 \mathrm{~nm}$.

The chemical composition of hard inclusions can be very diverse, both in terms of the components present in them as well as their share. Iron and silicon are the most frequently observed in these types of inclusions, but manganese, chromium and phosphorous are also often found. Depending on the share of sulfur in the brass, manganese and zinc sulphides can also be formed (Fig. 1). The strong reduction in iron solubility in copper (Fig. 2), which is additionally influenced by silicon, promotes the formation of hard inclusions.

S. Lassmann's research [5] showed that such phases can be formed when the iron content in the brass exceeds $0.03 \mathrm{wt} . \%$ and silicon $0.002 \mathrm{wt} . \%$. At the trace content of silicon in brass, inclusions do not occur even at the content of 0.1 wt.\% iron. 


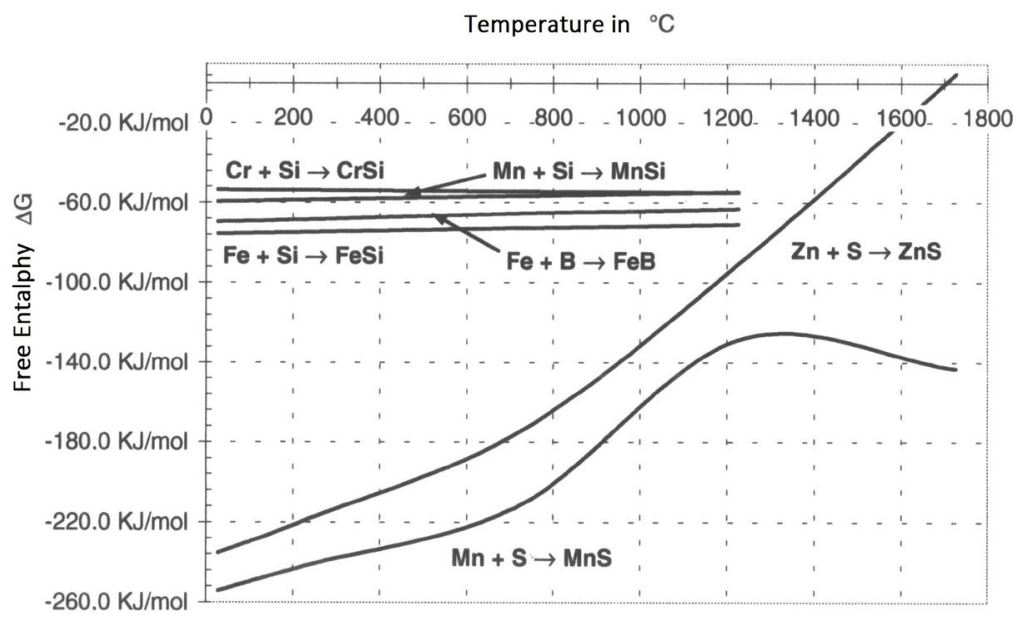

Fig. 1. Thermodynamic diagram of the formation of selected silicides and sulphides [6]

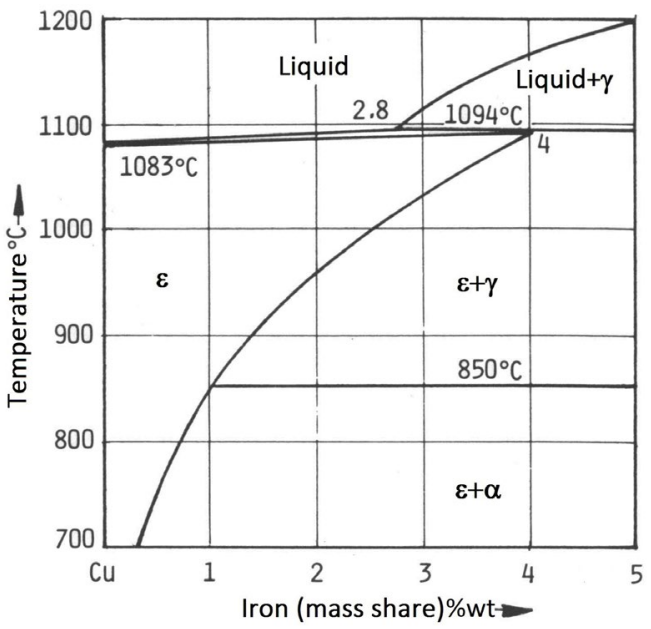

Fig. 2. Equilibrium diagram of $\mathrm{Cu}-\mathrm{Fe}[7]$

\section{DESCRIPTION OF THE RESEARCH}

The research was aimed at determining which armature brass from metallurgical pigs ensures that hard inclusions in the castings made of armature brass are avoided due to their chemical composition. For this purpose, samples were taken from metallurgical piglets of three brass fittings with different chemical compositions, as can be seen in Table 1. Of fundamental importance are the differences of iron and silicon content, that is the components most often found in hard inclusions.

Table 1

Chemical composition of chosen brass fittings

\section{Chemical composition [wt.\%]}

\begin{tabular}{|c|c|c|c|c|c|c|c|c|c|c|c|c|c|}
\hline \multirow{2}{*}{$\begin{array}{l}\text { No. of } \\
\text { sample }\end{array}$} & \multirow[b]{2}{*}{$\mathrm{Cu}$} & \multirow[b]{2}{*}{$\mathbf{P b}$} & \multirow[b]{2}{*}{ Sn } & \multirow[b]{2}{*}{ Al } & \multirow[b]{2}{*}{$\mathbf{F e}$} & \multirow[b]{2}{*}{$\mathbf{N i}$} & \multirow[b]{2}{*}{ Mn } & \multirow[b]{2}{*}{$\mathbf{P}$} & \multirow[b]{2}{*}{ As } & \multirow[b]{2}{*}{$\mathbf{S i}$} & \multirow[b]{2}{*}{ Bi } & \multirow[b]{2}{*}{$\mathbf{S b}$} & \multirow[b]{2}{*}{$\mathrm{Zn}$} \\
\hline & & & & & & & & & & & & & \\
\hline 1 & 58.28 & 1.62 & 0.47 & 0.23 & 0.31 & 0.10 & 0.04 & 0.004 & 0.007 & 0.08 & 0.001 & 0.001 & rest \\
\hline 2 & 57.84 & 1.38 & 0.32 & 0.05 & 0.21 & 0.08 & 0.02 & 0.004 & 0.004 & 0.11 & 0.001 & 0.006 & rest \\
\hline 3 & 59.21 & 1.20 & 0.06 & 0.61 & 0.08 & 0.02 & 0.01 & 0.009 & 0.006 & 0.006 & 0.001 & 0.006 & rest \\
\hline
\end{tabular}


Analyzes of hard inclusions in the tested alloys were made on the basis of tests using an Epityp 2 optical microscope and a JSM-5600 LV electron scanning microscope with EDS 2000 microanalyzer.

The test results are illustrated in Figures 3-14. The microstructure of brass with the highest iron content of 0.31 wt.\% (sample no. 1) is presented in Figures 3, 4 and 5.

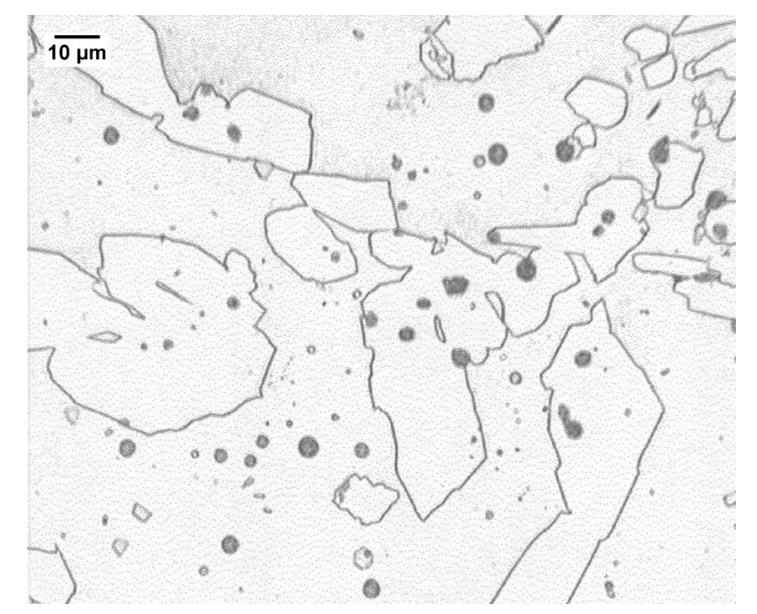

Fig. 3. Microstructure of brass sample no. 1, mag. 500×

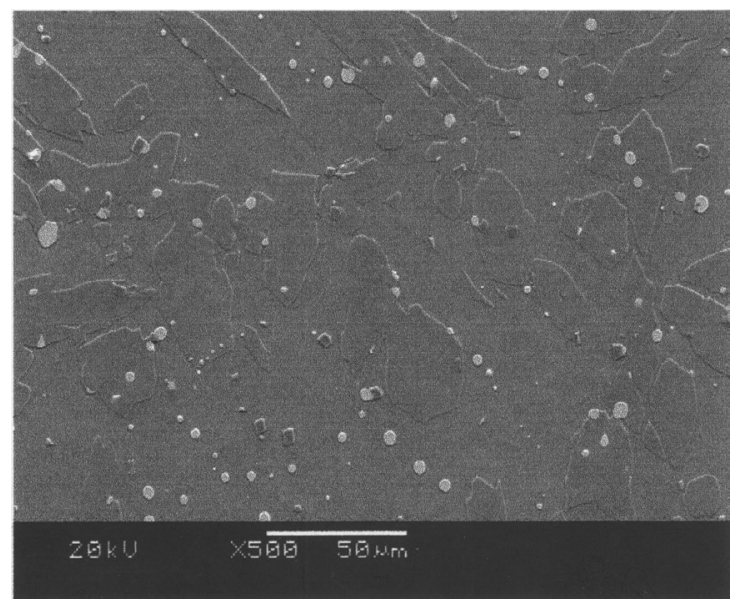

Fig. 4. Microstructure of brass sample no. 1 (SEM)

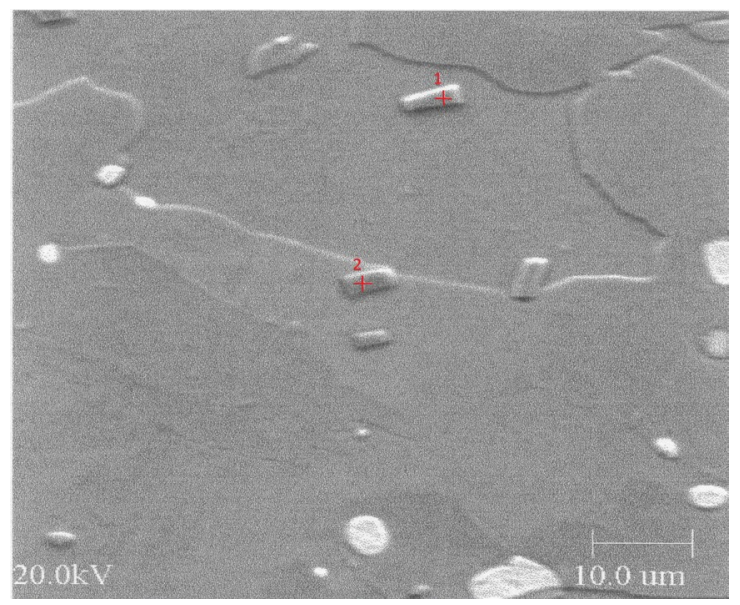

Fig. 5. Microstructure of brass sample no. 1 (SEM), mag. 2000×
In Figure 3 there are visible precipitations of lead in the form of rounded dark color separations. Numerous hard inclusions are characterized by angular shapes and a light gray color. In Figure 4, lead separations are characterized by a light gray color, while hard inclusions are characterized by a darker color and angular crystals. The hard inclusions are clearly visible in Figure 5, which shows their elongated and angular shapes. Figures 6 and 7 present energy spectra of two hard inclusions.

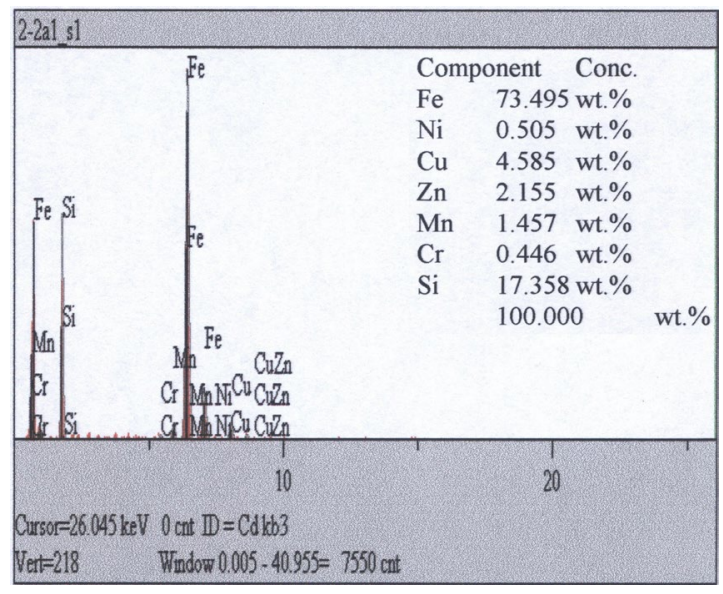

Fig. 6. The energy spectrum of inclusions 1 in brass sample no. 1

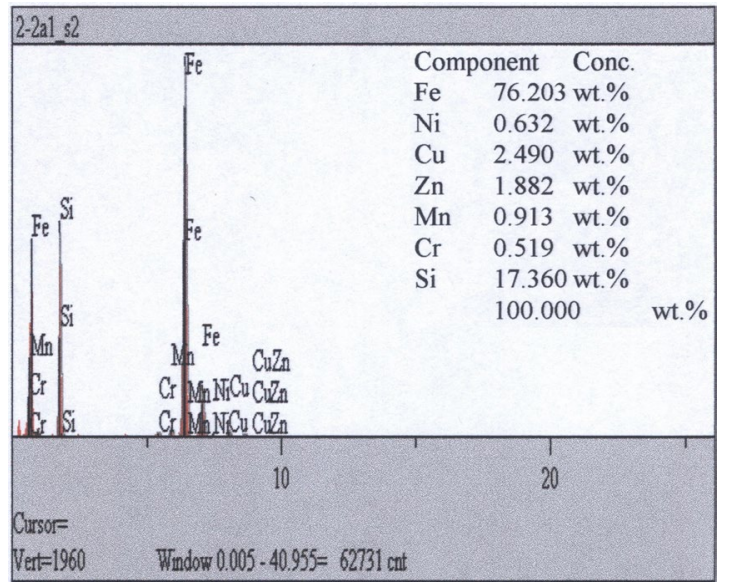

Fig. 7. The energy spectrum of inclusions 2 in brass sample no. 1

As a result, the dominant share in inclusions are enjoyed by elements as: iron and silicon by a lower share of nickel, manganese, chromium and also copper and zinc. Measurements of the number of hard inclusions showed that their participation in the sample of brass No. $1(0.31 \mathrm{wt} . \% \mathrm{Fe})$ was very large and it was 1183 per square millimeters.

The microstructure of brass no. $2(0.21 \mathrm{wt} . \% \mathrm{Fe})$ is illustrated in Figures 8 and 9. In Figure 8, lead separations of dark gray and rounded shape as well as small light gray separations of hard inclusions can be observed. The diversity of these inclusions can be more clearly seen in Figure 9 (SEM) on which the lead separations are bright and rounded, while the hard inclusions are dark gray with angular shapes. 


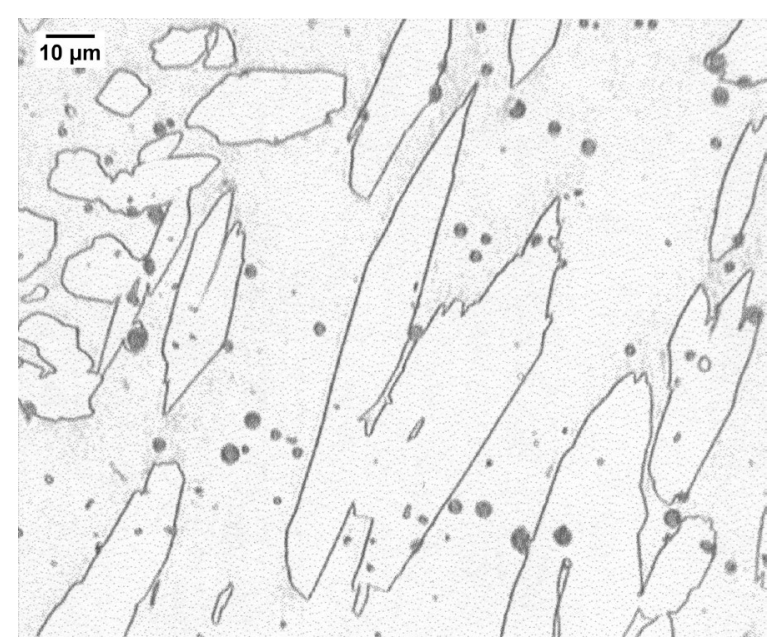

Fig. 8. Microstructure of brass sample no. 2, mag. 500×

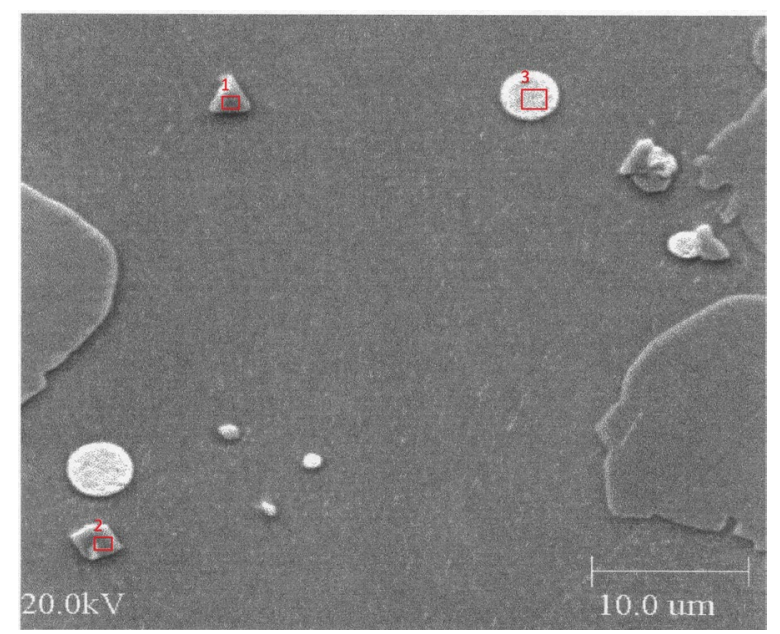

Fig. 9. Microstructure of brass sample no. 2 (SEM)

Figures 10 and 11 show energetic spectra of two hard inclusions. They show that the dominant share in these inclusions exhibit such elements as iron and silicon with a much smaller share of phosphorus, manganese, copper, zinc and chromium.

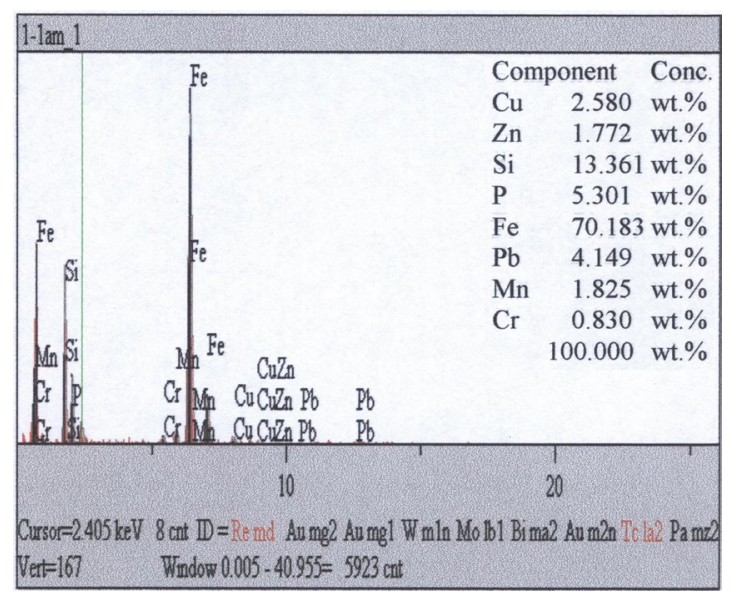

Fig. 10. The energy spectrum of inclusions 1 in brass sample no. 2

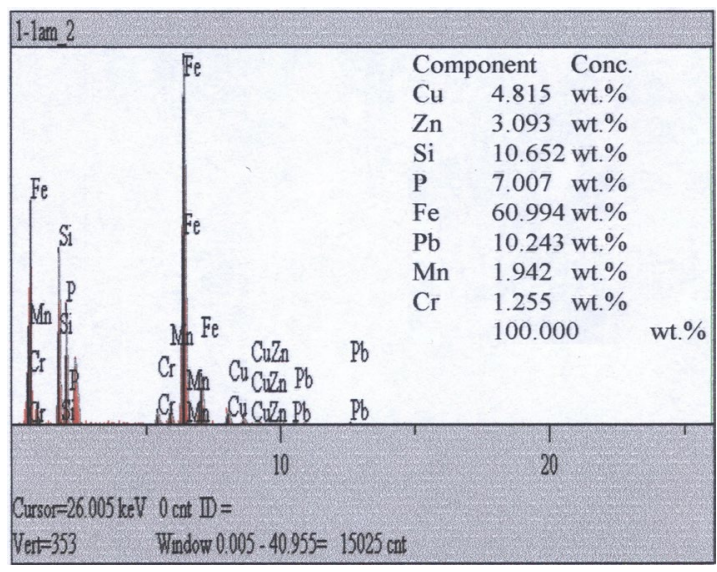

Fig. 11. The energy spectrum of inclusions 2 in brass sample no. 2

Measurement of the amount of hard inclusions showed that their participation in the brass sample no. 2 ( $0.21 \mathrm{wt} . \% \mathrm{Fe})$ was large and amounted to 933 per square millimeters.

The microstructure of the brass sample no. 3 (0.08 wt.\% Fe) is illustrated in Figures 12 and 13. Both figures show dark gray rounded lead separations, while hard precipitations of hard inclusions are not discerned.

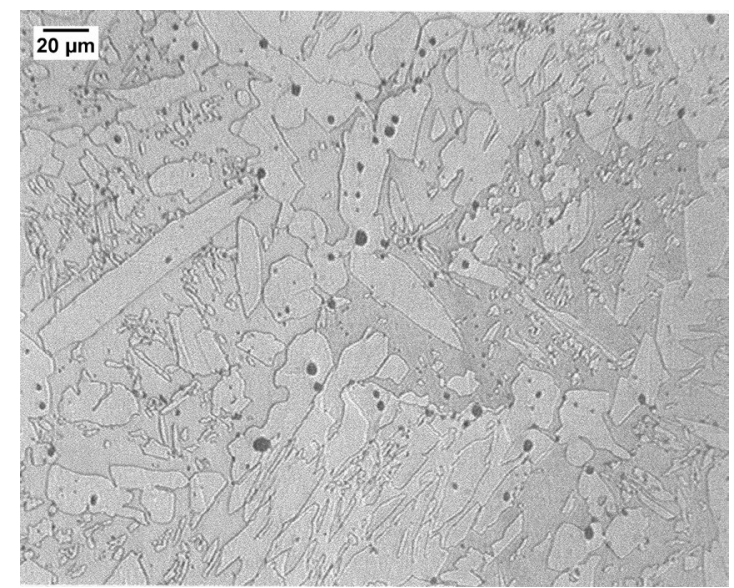

Fig. 12. Microstructure of brass sample no. 3, mag. 250×

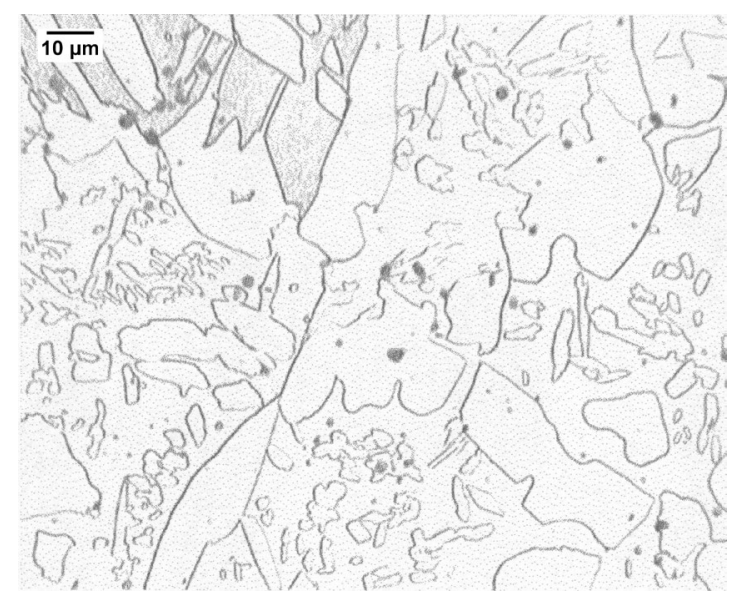

Fig. 13. Microstructure of brass sample no. 3, mag. 500× 
This is also confirmed by Figure 14, where the lead separations are light gray, while no dark precipitations of hard inclusions are observed.

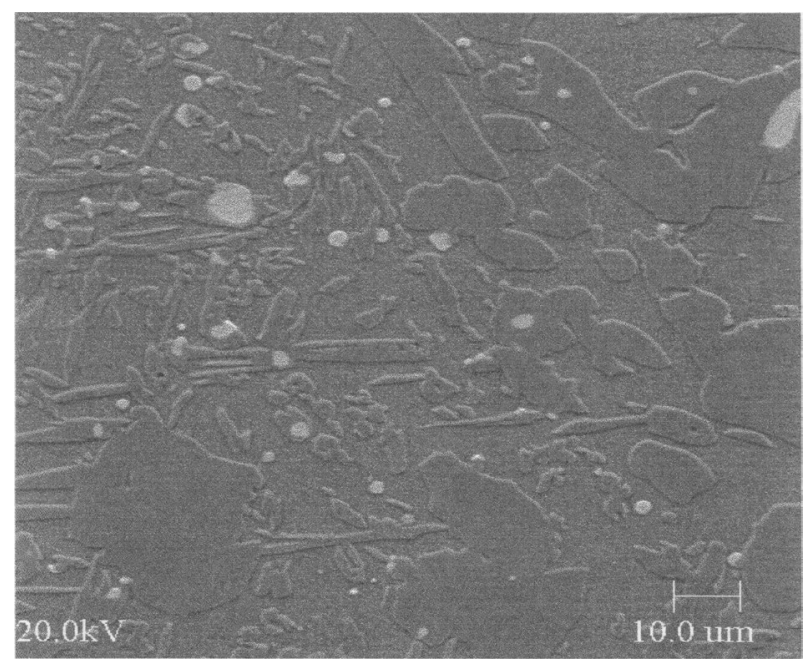

Fig. 14. Microstructure of brass sample no. 3 (SEM)

\section{ANALYSIS OF RESEARCH RESULTS}

The test results showed that in armature brass with iron content above $0.08 \mathrm{wt} . \%$ there are large amounts of hard inclusions. However, the number and size of mentioned inclusions increase with the increasing share of iron and silicon in the brass. In the sample of brass no. 1 with $0.31 \mathrm{wt} . \% \mathrm{Fe}$ and $0.08 \mathrm{wt} . \%$ Si there was a very large quantity of hard inclusions amounting to 1183 per square millimeters. With the smaller share of iron (0.21 wt.\%) in brass sample no. 2, the number of hard inclusions decreased to 933 per square millimeters despite the slightly higher silicon content ( $0.11 \mathrm{wt} . \%)$ in comparison to brass sample no. 1 .

Table 2 shows that hard inclusions in armature brass are intermetallic phases, the main components of which are iron and silicon. The share of these components changes in various inclusions from 60-76 wt.\% for iron and 10.6-17.4 for silicon. Hard inclusions also contain such components as chromium and manganese in small amounts as well as phosphorus and nickel, which occur in some inclusions. The registered share of copper, zinc and lead may occur in inclusions but may also originate from the alloy matrix.

The examination of brass sample no. 3 with a significantly reduced content of iron (up to $0.08 \mathrm{wt} . \%$ ) and silicon (up to 0.006 wt.\%) and nickel (up to 0.02 wt.\%) and manganese (up to $0.01 \mathrm{wt} . \%$ ), showed no visible hard inclusions in the alloy structure.

\section{CONCLUSIONS}

The research of samples that were taken from metallurgical pigs of armature brass with varying chemical compositions have shown that a decisive influence on the formation of hard inclusions is the contribution of components such as iron and silicon. These components have a dominant share in hard inclusions (60-76 wt.\% Fe and 10.6-17.4 wt.\% Si). In much smaller quantities there are also elements such as manganese, phosphorus, nickel and chromium in the inclusions. The number and size of hard inclusions depends on the contribution of iron and silicon brass. In the brass sample with 0.31 wt.\% Fe and 0.08 wt.\% Si, 1183 inclusions per square millimeters were identified, while in the brass sample with $0.21 \mathrm{wt} . \% \mathrm{Fe}$ and $0.11 \mathrm{wt} . \% \mathrm{Si}$ the amount of hard inclusions was reduced to 933 inclusions per square millimeters. In the brass sample in which iron content was reduced to $0.08 \mathrm{wt} . \%$ and silicon content was reduced to 0.006 wt.\%, no hard inclusions were identified.

\section{Acknowledgment}

M.R.D., K.K.D., W.W. acknowledge the financial support from the program of the Polish Ministry of Science and Higher Education under the name "Regional Initiative of Excellence" in 2019-2022, project no. 003/RID/2018/19, funding amount 11936596.10 PLN.

Table 2

The chemical composition of hard inclusions

\begin{tabular}{|c|c|c|c|c|c|c|c|c|c|c|}
\hline \multirow{2}{*}{$\begin{array}{l}\text { No. of } \\
\text { sample }\end{array}$} & \multirow{2}{*}{$\begin{array}{c}\text { No. of } \\
\text { inclusion }\end{array}$} & \multicolumn{9}{|c|}{ Chemical composition [wt.\%] } \\
\hline & & $\mathbf{F e}$ & $\mathbf{S i}$ & $\mathbf{N i}$ & Mn & $\mathbf{P}$ & $\mathrm{Cr}$ & $\mathrm{Cu}$ & Zn & $\mathbf{P b}$ \\
\hline \multirow{2}{*}{1} & 1 & 73.495 & 17.358 & 0.505 & 1.457 & - & 0.446 & 4.585 & 2.155 & - \\
\hline & 2 & 76.203 & 17.360 & 0.632 & 0.913 & - & 0.519 & 2.490 & 1.882 & - \\
\hline \multirow{2}{*}{2} & 1 & 70.183 & 13.361 & - & 1.825 & 5.301 & 0.830 & 2.580 & 1.772 & 4.149 \\
\hline & 2 & 60.994 & 10.452 & - & - & 7.007 & 1.255 & 4.815 & 3.093 & 10.243 \\
\hline
\end{tabular}




\section{REFERENCES}

[1] Kondracki M., Gawroński J. \& Szajnar J. (2005). Role of the interaction of elements in the forming of properties of foundry copper alloys designed for fittings. Foundry Journal, 4, 242-242.

[2] Kondracki M., Gawroński J., Szajnar J., Grzelczak R. \& Podsiadło K. (2002). Crystallization process investigation of the leaded brass M059 with TDA. Archives of Foundry Engineering, 4, 128-134.
[3] Romankiewicz F. \& Reif W. (1994). Intermetallic inclusions in leaded brass. Lower Silesian Conference: Copper alloys, 2022.04.1994. Wrocław-Szklarska Poręba, 213-219.

[4] Romankiewicz F. \& Romankiewicz R. (2006). Untersuchung der Harteinschlüsse in Armaturenmessing. Fortschrifte in der Metallographie, 38, 265-269.

[5] Lassmann S. (2000). Hard spots in copper-zinc alloys and their interpretation. Zeitschrift für Metallkunde, 91 (10), 868-873.

[6] Lassmann S. (2003). Untersuchung von Hart-spots in Kupfer-Zink-Legierungen und deren Deutung. Berlin: Shaker Verlag.

[7] Brunhuber E. (1991). Foundry-Lexicon. Berlin: Schiele und Shön. 